\title{
An Analysis of the Workforce Pipeline in School Psychology
}

\author{
Julie Q. Morrison ${ }^{1}$ (D) S Susan C. Davies ${ }^{2} \cdot$ Amity Noltemeyer $^{3}$
}

Accepted: 31 August 2020 / Published online: 3 September 2020

(C) California Association of School Psychologists 2020

\begin{abstract}
Shortage of school psychologists in the USA jeopardizes the capacity of schools to meet the needs of struggling students. The aim of the study was to evaluate the progression of school psychologists through the professional preparation - to practice pipeline for attracting, preparing, and retaining school psychologists. Descriptive research methods were used to retrospectively track three annual cohorts of graduate students from eight school psychology programs as they progressed through key milestones in their preparation and early professional practice. The results indicate that a large percentage of students completed their graduate program and continued to work in the field 1-, 3-, and 5-year post-internship for a sample that was predominately White and female. The implications of the study reinforce previous calls for graduate programs to engage in targeted, personalized efforts for recruiting graduate students with minoritized cultural identities to better meet the needs of students from culturally and linguistically diverse backgrounds.
\end{abstract}

Keywords Professional issues in school psychology $\cdot$ Training in school psychology $\cdot$ Diversity

School psychologists provide an array of academic and mental health services to support students and schools. However, a significant shortage of school psychologists in the USA jeopardizes the capacity of schools to meet the needs of all students and this personnel shortage is predicted to persist into the foreseeable future (American Association for Employment in Education 2016; Castillo et al. 2014). Ongoing shortages in underserved areas are particularly acute and some positions have remained unfilled for many years (National Association of School Psychologists 2017).

Several trends help account for the increasing demand for school psychologists. The overall number of school-age students has increased as well as the number of students with recognized academic and behavioral needs. According to the National Center for Education Statistics (2017), the total number of students in public schools rose by $6.6 \%$ from 2000 to 2014 (from $47,203,539$ to $50,312,581$ ), with a projected increase to $51,737,900$ by 2026 . One in six children aged $2-$

Julie Q. Morrison

Julie.Morrison@uc.edu

1 CECH-School of Human Services, School Psychology Program, University of Cincinnati, P.O. Box 210068,

Cincinnati, OH 45221-0068, USA

2 University of Dayton, Dayton, OH, USA

3 Miami University, Oxford, OH, USA
8 years (17.4\%) had a diagnosed mental, behavioral, or developmental disorder in 2016 (Cree et al. 2018). Increased student populations with intensified needs combined with a shortage of school psychologists threaten the availability and quality of school psychological services. School psychologist shortages, further compounded by an aging population of professionals, are predicted to continue through 2025 (Castillo et al. 2014).

The shortage of school psychologists contributes to large caseloads and unfavorable ratios in the field. The National Association of School Psychologists recommends that a school psychologist serves no more than 1000 students in general and no more than 700 students when comprehensive or preventative services are being provided. Yet the ratio of students per school psychologist was estimated to be 1381 to 1 in the 2014-2015 school year (Walcott and Hyson 2018). In 2009-2010, only seven states met the recommended 1000:1, and 23 states had ratios that exceeded 1500:1 (NASP 2011).

The shortage of school psychologists who are culturally and linguistically diverse (that is, historically underrepresented or minoritized in the USA) is particularly acute as student populations are becoming increasingly culturally and linguistically diverse (Proctor and Romano 2016). Although White students historically represented the majority of students in US public schools, racial and ethnic minority students now comprise a majority of public school students (Hussar et al. 2020). Studies suggest that better mental health treatment outcomes are attained when mental health providers are racially/ ethnically similar to those that they serve (e.g., Bernal et al. 
2009; Griner and Smith 2006). Yet, approximately $87 \%$ of school psychologists are White and $86 \%$ are fluent in English only (Walcott and Hyson 2018). Increasing the number of diverse school psychologists can help create a workforce of practitioners with racial sensitivity and awareness to advocate for and provide mental health services to children from racial and ethnic minority communities. This is of particular importance when students are affected by racially motivated violence, discrimination, and inequities, such as the impact of COVID-19 on communities of color.

Multiple factors have been suggested as contributing to the shortage of school psychologists. These factors include a shortage of qualified faculty, limited access to NASPapproved graduate programs in certain parts of the country, a limited number of qualified applicants for some programs, difficulty attracting graduates into areas where vacancies occur, difficulties retaining qualified school psychologists, and a shortage of approved internships and qualified supervisors (NASP 2016). The impact of unfavorable ratios on school psychologists' roles may influence practitioners' perceptions of job satisfaction (Brown and Sobel 2019), thus further exacerbating personnel shortages as practitioners exit the profession to find more satisfying jobs.

Efforts to counter the shortages of school psychologists focus on recruitment, graduate preparation, and retention strategies. Recruitment strategies include campaigns to increase awareness of the profession, incentives for entering graduate preparation programs, and outreach to high school and undergraduate students (NASP 2016). Targeted strategies to recruit cultural and linguistic diversity of school psychologists include promoting the benefits of (a) advocating for children from minoritized cultural backgrounds, (b) connecting with parents from minoritized cultural backgrounds, and (c) challenging racial bias and championing social justice (Truscott et al. 2014). Graduate programs with diverse faculty are better able to recruit diverse students by promoting the perception of graduate school as an inclusive and welcoming environment with opportunities for mentorship and to contribute to research that advances multiculturalism, diversity, and social justice (Proctor and Romano 2016).

Strategies to support program completion for graduate students from minoritized cultural backgrounds include mentoring, financial assistance, field experiences involving children from minoritized cultural backgrounds, and research opportunities related to diversity issues (Proctor and Truscott 2012; Rogers and Molina 2006). Having a critical mass of diverse students helps create an environment that values, accepts, and welcomes racially and ethnically diverse students (Rogers and Molina 2006). In fact, students who participate in graduate coursework with individuals from diverse backgrounds experience deeper and more meaningful learning, which translates into greater cultural competence (Newell et al. 2010).
Retention strategies for early career school psychologists include mentoring and induction programs that feature culturally informed mentorship and peer relationship building, increasing alignment with the role and responsibilities of the position with the National Association of School Psychologists (NASP 2020) Model for Comprehensive and Integrated School Psychological Services, evaluating performance consistent with the NASP model, providing strong and responsive supervision and supporting ongoing professional growth, and advocating for increasing the number of and opportunities for school psychologists (NASP 2016).

Yet all of these efforts to address the shortage problem will only be in vain unless they are tailored to the particular concern contributing to the shortage. Given the lack of clarity regarding the factors contributing to the shortage of school psychologists and the absence of empirical evidence to support these assertions (Mann et al. 2019), a systematic analysis is needed to pinpoint where attrition is most likely to occur in the progression from graduate student applicant to seasoned practitioner.

A workforce pipeline analysis is a data-based approach to answering questions about workforce supply and demand issues (Rozensky et al. 2007). A critical analysis of the pipeline makes it possible to pinpoint weaknesses in the pipeline and generate target strategies to address the weaknesses. Workforce pipeline analyses have been used to assess the supply of graduate students and the demand for internship training in psychology (Rozensky et al. 2007) and to pinpoint factors contributing to the shortage of special education teachers (Brownell et al. 2019). The American Psychological Association approved the creation of the APA Center for Psychology Workforce Analysis and Research in 2006. As its primary resolution, the Center identified the need for more systematic data collection at the national, regional, and program levels to consider supply, demand, need, and context in an integrated and comprehensive manner (Rozensky et al. 2007). One analysis, the "Psychology Pipeline," involves describing the gender, race/ethnicity, and counts at the various stages of career progress (Rozensky et al. 2007, p. 242). Yet, despite calls for a better understanding of the pipeline, there have been no known studies published in the research literature to date in psychology in general nor in school psychology specifically. The aim of the current study was to fill this gap in the professional literature by evaluating the progression of school psychologists through the preparation-to-practice pipeline. The research questions addressed in this study were as follows:

1. What percentage of school psychology graduate students progress through the workforce pipeline and remain in the profession 1 year, 3 years, and 5 years after internship?

2. What percentage of school psychology graduate students progress through the workforce pipeline and remain in the 
profession 1 year, 3 years, and 5 years after internship by race/ethnicity?

3. What percentage of school psychology graduate students receiving a state-funded internship progress through the workforce pipeline and remain in state and in the profession 1 year, 3 years, and 5 years after internship?

\section{Method}

\section{Sample}

Educational Specialist Sample The sample included 236 graduate students pursuing an Educational Specialist (Ed.S.) degree in a school psychology graduate program. The graduate students completed a state-funded internship during the 2012$2013(n=75), 2013-2014(n=81)$, and 2014-2015 $(n=80)$ school years. Graduate preparation programs from eight of the nine universities with school psychology programs in Ohio contributed to the Ed.S. sample. One of the eight graduate programs was recently established and only contributed data for one cohort (2014-2015) to the sample. The vast majority (i.e., 228 or $96.6 \%$ ) of the graduate students completed a fulltime program, with only eight graduate students from one university completing a part-time program. The sample was predominately female, with $86.0 \%(n=203)$ of the graduate students identifying as female and $14.0 \%(n=33)$ identifying as male. The majority of the sample was White $(n=225$, $95.3 \%$ ), with a small proportion of graduate students identifying as Black or African $(n=8,3.4 \%)$, Asian $(n=2,0.8 \%)$, and Native American $(n=1,0.4 \%)$.

Doctoral Sample The sample included 23 graduate students pursuing a Doctoral (Ph.D.) degree in a school psychology graduate program. The graduate students completed their state-funded internship during the 2012-2013 $(n=8), 2013-$ $2014(n=9)$, and 2014-2015 $(n=6)$ school years. Graduate preparation programs from three of the participating universities in Ohio contributed to the Ph.D. sample. Twenty-two graduate students in the Ph.D. sample identified as female and one identified as male. The majority of the sample was White $(n=21,91.3 \%)$, with one graduate student identifying as Black or African and one graduate student identifying as Hispanic.

\section{Setting}

Samples for this study were selected from cohorts of school psychology interns participating in a state-funded internship in Ohio. The Ohio Department of Education invested in the development of school psychologists through the Ohio Internship Program in School Psychology (Morrison et al.
2009). Internship sites must be reviewed and approved by the school psychology faculty according to the procedures specified in the Operating Manual (Ohio Department of Education 2015). In accepting a state-funded internship, participating interns must commit in writing to give at least 1 year of service as a school psychologist in Ohio.

\section{Measures}

The measures used in this study focused on three key junctures in the professional preparation-to-practice pipeline: admission, graduate preparation, and retention in the field of school psychology.

Admission Measures The admission measures included the number of applications received for each incoming cohort and the admission yield rate. The admission yield rate, defined as the percentage of applicants enrolled in the graduate program, was calculated for the incoming graduate cohort that became the internship cohorts of 2014-2015, 2013-2014, and 2012-2013.

Graduate Preparation Measure Graduate preparation completion rates were calculated as the percentage of graduate students who completed their graduate coursework in order to meet the requirements to begin their internship. Graduate preparation completion rates calculated for the graduate students in the internship cohorts of 2014-2015, 2013-2014, and 2012-2013.

The race/ethnicity and gender of graduate students who did not complete their graduate preparation were noted. Internship counts included the number of graduate students completing a school psychology internship in each cohort. A separate count representing the number of graduate students completing the Ohio Internship Program was also recorded.

Retention Measures The retention measures were operationalized as the percentage of graduate students in each internship cohort (i.e., 2014-2015, 2013-2014, and 2012-2013) who continued to work in the field of school psychology 1 year, 3 years, and 5 years after their internship year. Retention measures were also calculated for the percentage of graduate students who completed their internship as part of the statefunded internship program who continued to work in Ohio as a school psychologist 1 year, 3 years, and 5 years after their internship year. The race/ethnicity and gender of school psychologists who left the profession within the first 5 years of completing their internship were noted. School psychology faculty were asked to record a reason for leaving the profession statement for each early career school psychologist who left the profession. The team of three researchers analyzed the content of the statements and developed a coding procedure that included the following codes: (a) career change—-low job 
satisfaction, (b) career change - no indication of low job satisfaction, (c) death, (d) family care, and (e) work-life balance/ job stress. An independent reviewer applied the coding procedure to assess interrater reliability, defined as the percentage of statements assigned a code that agreed with the research team's code. The percentage of agreements with the research team's code was $100 \%$.

\section{Design and Procedures}

Figure 1 provides a graphic representation of the pipeline analysis procedures used in this study. Descriptive research methods were used to retrospectively track graduate students by cohort as they progressed through key milestones in their graduate preparation and early professional practice. School psychology faculty at each of the participating universities were asked to begin with the internship cohort of 20142015 and determine each intern's professional retention status 1 year, 3 years, and 5 years following internship. An Excel spreadsheet was provided to the school psychology faculty member to structure the data collection process. Professional retention status for the samples was recorded as either (a) working as a school psychologist (practitioner or university faculty) within the state, (b) working as a school psychologist (practitioner or university faculty) in another state (specifying the state), or (c) no longer working as a school psychologist. School psychology faculty were not able to confirm the retention status for three interns in the Ed.S. sample $(1.2 \%$ of the sample). Two of the three were coded as no longer working in the profession 5 years following internship and one was coded as no longer practicing 3 years after internship, marking the point in time in which their status was unknown. School psychology faculty were asked to provide a brief statement regarding the reason for leaving the profession for each school psychology intern who left the profession within their first 5 years of practice. For each member of the 2014-2015 cohort, the race/ethnicity and gender of the intern were recorded. Next, the school psychology faculty were asked to record the number of graduate students that entered the school psychology program when the 2014-2015 internship cohort began their graduate studies and note the number of graduate students from this cohort who did not complete their graduate preparation and the race/ethnicity and gender of those who did not complete the graduate program. Finally, the school psychology faculty were asked to record the number of applications the program received for the incoming cohort the year the 2014-2015 interns began their graduate program. This same set of procedures was repeated for the internship cohort of 2013-2014 and 2012-2013.

\section{Results}

This study focused on three key junctures in the professional preparation-to-practice pipeline to better understanding how to address a shortage of school psychologists.

\section{Admission to Graduate Programs}

Among the 22 graduate student cohorts enrolled in an Ed.S. school psychology program at eight universities, the cohort size ranged from 7 to 19 graduate students, with a median count of 10 graduate students. The number of applications received for each of these graduate student cohorts ranged from 15 to 68 applications, with a median count of 53 applications per year. The admission yield rate for graduate students entering an Ed.S. graduate program ranged from 14.7 to $66.7 \%$, with a median admission yield rate of $23.0 \%$. Taken together, the incoming cohorts across 3 years from eight universities included 252 graduate students who were predominately female (85.8\%) and White (94.7\%).

Among the 9 graduate student cohorts enrolled in a Ph.D. school psychology program at one of three universities, the cohort size ranged from 1 to 4 graduate students, with a median count of 3 graduate students. The number of applications received for each of these graduate student cohorts ranged from 7 to 14 applications, with a median count of 10 applications per year. The admission yield rate for graduate students entering a Ph.D. program ranged from 18.2 to $42.9 \%$, with a median admission yield rate of $30.0 \%$. Taken together, the incoming Ph.D. graduate cohorts across 3 years from three universities included 23 graduate students who were predominately female (95.7\%) and White $(91.3 \%)$. Figure 2 presents the counts of students enrolled Ed.S. and Ph.D. programs.

\section{Graduate Preparation}

A large percentage of graduate students successfully completed their graduate coursework in order to meet the requirements to begin their internship. Among the 252 graduate
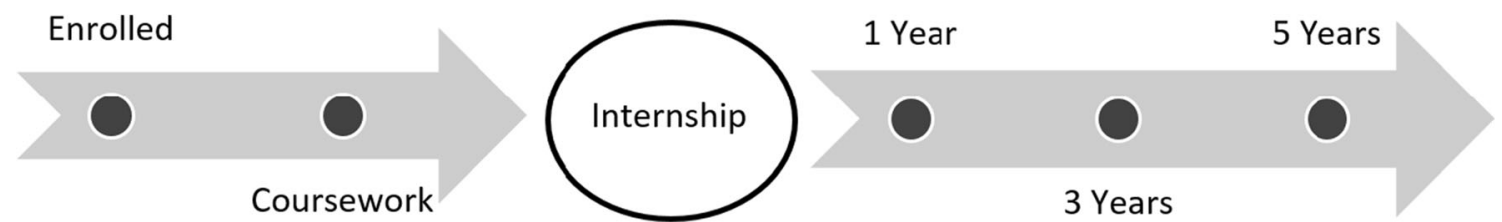

Fig. 1 School psychology pipeline analysis model. The model for the school psychology pipeline analysis identified the members of an internship cohort and tracked their progress forward for 5 years and retrospectively as they enrolled in the graduate preparation program 
Fig. 2 School psychology graduate student counts at each juncture in the pipeline. Number of school psychology graduate students progressing through graduate preparation, internship, and into professional practice 1 year, 3 years, and 5 years after internship: Ed.S. and Ph.D. cohorts

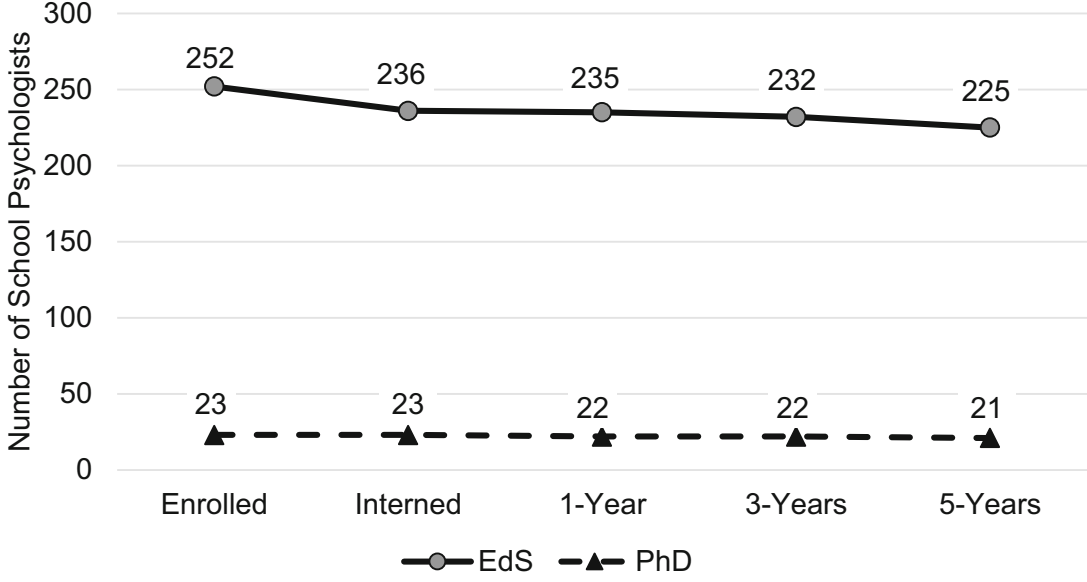

students enrolled in an Ed.S. school psychology program, 93.7\% successfully completed their graduate coursework requirements. Twelve (or 75.0\%) of the graduate students who did not complete their graduate preparation were White and the four other graduate students represented three different racial/ethnic identities. Further description of the race/ ethnicity of the students who did not complete their graduate programs could jeopardize the anonymity of these individuals.

Across the eight Ed.S. programs, two programs had completion rates of $100 \%$, one program had a $96.7 \%$ completion rate, and three programs each had two students as noncompleters for completion rates of $93.8 \%, 94.3 \%$, and $95.9 \%$. Two programs had notably lower rates of completion with White and culturally diverse students as non-completers. One program had an $89.3 \%$ completion rate while the other program had an $83.3 \%$ completion rate. The completion rates for these two programs suggest possible program-specific concerns that warrant further exploration. No exit interview data were gathered from the graduate students who left their programs prior to completion. The need to gather this important information is addressed in the "Discussion" section as an area for future research.

Among the 23 graduate students enrolled in a Ph.D. school psychology program, $100 \%$ successfully completed their graduate coursework requirements. Figure 2 presents the counts of Ed.S. and Ph.D. students who were subsequently placed in an internship.

\section{Retention of Early Career School Psychologists}

A large percentage of graduate students in each internship cohort (i.e., 2014-2015, 2013-2014, and 2012-2013) continued to work in the field of school psychology 1 year, 3 years, and 5 years after their internship year. Among the 236 interns from the Ed.S. sample, $99.6 \%$ were working in the field 1 year after their internship, $98.3 \%$ remained in the profession 3 years after internship, and $95.3 \%$ continued to work as school psychologists 5 years into their professional practice. Among the
11 early career school psychologists who left the profession in their first 5 years of practice, 9 were White and 2 were students with minoritized cultural identities. All but one were male. Among the 23 interns from the Ph.D. sample, 95.7\% were working as school psychologists in school, hospital, or university settings 1 year and 3 years after internship, and $91.3 \%$ continued to work as a school psychologist 5 years into their professional career. Only one early career school psychologist from the Ph.D. left the profession in the first 5 years of practice.

The reason for leaving the profession statements indicated that a variety of personal and professional factors unique to each individual contributed to a school psychologist's decision to leave the profession. No clear pattern emerged as to why a small percentage of school psychologists chose to leave the profession.

\section{Retention of Professionals Supported by the Ohio Internship Program in School Psychology}

The Ohio Department of Education has a vested interest in retaining school psychologists in state. The results indicate that a large percentage of graduate students in each internship cohort receiving a state-funded internship continued to work in Ohio as a school psychologist 1 year, 3 years, and 5 years after their internship year. Among the 236 interns from the Ed.S. sample, 227 (or 96.2\%) of the interns completed their internship in state. Among these Ohio interns, 97.8\% were working in Ohio in the field 1 year after their internship, $94.7 \%$ remained in state and in the profession 3 years after internship, and $89.9 \%$ continued to work as school psychologists in Ohio 5 years into their professional practice. The 14 school psychologists who moved out-of-state 5 years into their professional practice relocated to 9 different states.

At the Ph.D. level, graduate students are encouraged to conduct a national search for an internship through the APPIC process. Graduate students earning their Ph.D. are also prepared to pursue positions as university faculty to meet a 
national need. Despite these distinctions between the Ed.S. and Ph.D. students' preparation and future professional trajectories, the results indicate that a large percentage of Ph.D. graduate students received a state-funded internship and continued to work in Ohio as school psychologists 1 year, 3 years, and 5 years after their internship year. Among the 23 interns from the Ph.D. sample, 21 (or 91.3\%) completed their internship in state as part of the state-funded internship program. All 21 of the Ohio interns were working in Ohio and one additional intern returned from an out-of-state internship to work in Ohio 1 year after the internship. At the 3-year point in time, 21 of the Ph.D. cohort remained in state and in the profession. Five years into their professional practice, 19 interns continued to work as school psychologists in Ohio. The two Ph.D.level school psychologists who moved out-of-state relocated for a university faculty position.

\section{Discussion}

The shortage of school psychologists, left unaddressed, has the potential to reduce the quality and range of services to students and schools. It is critically important to understand the shortage and identify possible junctures in the workforce pipeline at which it could be mitigated. This study aimed to address this need by examining the degree to which eight school psychology graduate preparation programs in Ohio were effective in admitting graduate students who successfully completed their graduate preparation and remained in the field throughout their early career.

\section{Findings, Interpretations, and Implications for Practice}

Results from three annual cohorts of interns suggest that neither attrition from graduate programs nor attrition from the profession was a significant factor contributing to the shortage of school psychologists. In general, a large percentage of students successfully completed their graduate program and continued to work in the field 1,3 , and 5 years post-internship. Thus, the workforce pipeline in Ohio appears to be well suited for admitting, preparing, and retaining White, female school psychologists. Critically absent from the analysis is adequate representation of school psychologists from minoritized cultural backgrounds, further illuminating a dire need for efforts to attract more diverse applicants to school psychology graduate programs.

The implications of the current study reinforce previous calls for graduate programs to engage in ongoing, targeted, personalized efforts to recruit students with minoritized cultural identities, and consider providing financial support as a recruitment strategy and connecting with minority serving institutions (Proctor and Romano 2016). NASP (2016) also suggests an array of recruitment strategies for attracting diverse graduate students. General recruitment strategies include raising awareness of the profession, providing incentives in shortage-impacted areas, and increasing exposure to the profession through undergraduate coursework and advising (NASP 2016). Targeted strategies for recruiting and preparing students with minoritized cultural identities include embedding multicultural coursework and fieldwork opportunities into the curriculum, ensuring diverse faculty representation, implementing admissions procedures that yield a diverse student body, establishing connections with institutions that serve historically underrepresented populations, and emphasizing an ongoing commitment to diversity (NASP 2016). Programs should consider these recommendations in developing a plan for recruiting robust and diverse cohorts into their programs.

Beyond recruiting more diverse graduate students, it is important to also address graduate preparation completion disparities. Although the overall percentage of students exiting graduate preparation programs in this study was not concerning, students with minoritized cultural identities were disproportionately reflected in the counts of non-completers. Exit interview data were not gathered from the graduate students who left their programs prior to completion as part of this study, and yet the information garnered from these interviews would be critically important to understanding how programs support, or fail to support, all students and particularly students with minoritized cultural identities. Future research should explore the factors that contribute to noncompletion from the perspective of graduate students who leave their program.

The results of this study are consistent with research suggesting that students with minoritized cultural identities may experience unique barriers or challenges in the course of their graduate preparation (e.g., Proctor and Truscott 2012) and reveal the need to target graduate school preparation and retention efforts. Proctor and Owens' (2018) structured review on graduate school retention research in school psychology found only two studies that met their inclusion criteria, but both studies reported four shared retention strategies for students with minoritized cultural identities: (1) an inclusive program atmosphere, (2) access to diverse professional networks, (3) mentorship opportunities, and (4) program commitment to multicultural issues. The authors also recommended that programs conduct annual surveys with all students to assess retentionrelated issues (e.g., perceptions of belongingness, peer and faculty support) and meet with students with minoritized cultural identities to better understand their program-related experiences. These strategies should be considered by programs seeking to create an atmosphere conducive to retaining diverse students.

Therefore, a major implication of this study is that the workforce pipeline was generally effective in preparing and 
retaining school psychologists who entered graduate programs, with a critical need to improve supports for preparing students with minoritized identities. Thus, a key to preparing school psychologists to meet workforce needs may be to build programs' capacity to adjust their enrollments (either expanding or contracting flexibly), to be responsive to workforce trends.

A final implication of this study has relevance to the state investment in an internship program in school psychology. Ohio is one of the few, if only, states with a state-funded internship. As part of the Ohio Internship Program, sites must be reviewed and approved and participating interns must commit to give at least 1 year of service as a school psychologist in Ohio. The results indicate that a very high percentage of school psychologists remain in Ohio 1 year, 3 years, and 5 years after completing their state-funded internship. Thus, the state's investment in preparing future school psychologists to support Ohio schools seems to be well placed.

\section{Limitations and Future Directions for Research}

Although this study represents an important contribution to understanding a pressing problem in the field, there are limitations that must be considered when interpreting the results. First, the counts of students entering, completing graduate programs, and remaining in the field were collected by graduate program faculty and were not independently verified. Future research should incorporate procedures for verifying graduate program data and plan for additional analyses, such as examining whether retention rates vary by region, school/ district characteristics, or graduate preparation program. Furthermore, the study lacked assessment of potential variables that may influence attrition and recruitment at various stages in the pipeline. Finally, the data were collected in only one state, a state (a) experiencing a shortage, and (b) with a longstanding commitment to the preparation of school psychologists through a state-funded internship. As such, the results might not be representative of the workforce pipeline in other states. A workforce pipeline analysis may be valuable on a national scale to inform state and regional efforts to address school psychologist shortages.

\section{Conclusions}

This study aimed to examine the workforce pipeline to understand and address the shortage of school psychologists. Measures related to the admission, graduate preparation, and retention of school psychologists were analyzed across three annual cohorts of school psychologists in Ohio. Findings revealed the need for a commitment to targeted recruitment and preparation supports to promote greater cultural and linguistic diversity in the profession. By more systematically monitoring the workforce pipeline, while concurrently implementing effective practices to recruit and prepare graduate students from minoritized cultural backgrounds for success in the profession, it is our hope that the shortage can be mitigated.

Acknowledgments The authors would like to acknowledge the members of the Inter-University Council for Ohio School Psychology for their contributions to this study.

\section{Compliance with Ethical Standards}

Conflict of Interest The authors declare that they have no conflict of interest.

Ethical Approval This study involved the analysis of a pre-existing data set. All procedures performed in studies were in accordance with the ethical standards of the Institutional Review Board (IRB).

Informed Consent The study was reviewed by the Institutional Review Board. Informed consent was not required as the study involved an analysis of a pre-existing data set.

\section{References}

American Association for Employment in Education. (2016). Educator supply and demand report 2015-2016: executive summary. Author.

Bernal, G., Jimenez-Chafey, M. I., \& Domenech Rodriguez, M. M. (2009). Cultural adaptations of treatments: a resource for considering culture in evidence-base practice. Professional Psychology: Research and Practice, 40, 361-368. https://doi.org/10.1037/ a0016401.

Brown, T. J., \& Sobel, D. (2019). School psychologists' job attitudes: a systematic review. Contemporary School Psychology. https://doi. org/10.1007/s40688-019-00241-4.

Brownell, M., Holdheide, L., \& Ziegler, D. (2019). Special education teacher and early intervention provider shortages. Indianapolis: Presentation at the annual convention of the Council for Exceptional Children.

Castillo, J. M., Curtis, M. J., \& Tan, S. Y. (2014). Personnel needs in school psychology: a 10 year follow-up study on predicted personnel shortages. Psychology in the Schools, 51(8), 832-849. https:// doi.org/10.1002/pits.21786.

Cree, R. A., Bitsko, R. H., Robinson, L. R., Holbrook, J. R., Danielson, M. L., Smith, C., Kaminski, J. W., Kenney, M. K., \& Peacock, G. (2018). Health care, family, and community factors associated with mental, behavioral, and developmental disorders and poverty among children aged 2-8 years - United States, 2016. Morbidity and Mortality Weekly Report, 67, 377-1383. https://doi.org/10.15585/ mmwr.mm6750a1.

Griner, D., \& Smith, T. B. (2006). Culturally adapted mental health intervention: a meta-analytic review. Psychotherapy: Theory, Research, Practice, Training, 43, 531-548. https://doi.org/10. 1037/0033-3204.43.4.531.

Hussar, B., Zhang, J., Hein, S., Wang, K., Roberts, A., Cui, J., Smith, M., Bullock Mann, F., Barmer, A., and Dilig, R. (2020). The condition of education 2020 (NCES 2020-144). U.S. Department of Education. Washington, DC: National Center for Education Statistics. https://nces.ed.gov/pubsearch/pubsinfo. asp?pubid= 2020144.

Mann, A., Castillo, J., \& Myers, M. A. (2019). A case example of one state's efforts to measure and address the critical shortage of school 
psychologists. Psychology in the Schools, 56, 1716-1736. https:// doi.org/10.1002/pits.22297.

Morrison, J. Q., Graden, J. L., \& Barnett, D. W. (2009). Steps to evaluating a state-wide internship program: model, trainee, and student outcomes. Psychology in the Schools, 46(10), 989-1005. https://doi. org/10.1002/pits.20439.

National Association of School Psychologists. (2020). Model for comprehensive and integrated school psychological services. Bethesda: Author.

National Association of School Psychologists. (2016). Addressing shortages in school psychology: resource guide. Bethesda: Author https://www.nasponline.org/resources-and-publications/resourcesand-podcasts/school-psychology/shortages-in-school-psychologyresource-guide.

National Association of School Psychologists. (2011). Ratio of students per school psychologist by state: data from the 2009-2010 and 2004-2005 NASP membership surveys. Bethesda: Author http:// www.nasponline.org/research-and-policy/nasp-research-center/ school-psychology-workforce.

National Association of School Psychologists. (2017). Shortages in school psychology: challenges to meeting the growing needs of U.S. students and schools [Research summary]. Bethesda: Author.

National Center for Education Statistics (2017). Digest of education statistics: 2016 (Table 203.20). Washington: U.S. Department of Education, Institute for Education Sciences, National Center for Education Statistics.

Newell, M. L., Nastasi, B. N., Hatzichristou, C., Jones, J. M., Schanding, T., \& Yetter, G. P. (2010). Evidence on multicultural training in school psychology: recommendations for future directions. School Psychology Quarterly, 25, 249-278. https://doi.org/10.1037/ a0021542.

Ohio Department of Education. (2015). The Ohio internship in school psychology: guidelines and operating manual. Columbus: Ohio Department of Education and the Inter-University Council for Ohio School Psychology.

Proctor, S. L., \& Owens, C. (2018). School psychology graduate education retention research characteristics: implications for diversity initiatives in the profession. Psychology in the Schools, 56, 1037-1052.

Proctor, S. L., \& Romano, M. (2016). School psychology recruitment research characteristics and implications for increasing racial and ethnic diversity. School Psychology Quarterly, 31, 311-326.

Proctor, S. L., \& Truscott, S. D. (2012). Reasons for African American student attrition from school psychology programs. Journal of School Psychology, 50, 655-679.
Rogers, M. R., \& Molina, L. E. (2006). Exemplary efforts in psychology to recruit and retain graduate students of color. American Psychologist, 61, 143-156. https://doi.org/10.1037/0003-066X.61. 2.143 .

Rozensky, R. H., Grus, C. L., Belar, C. D., Nelson, P. D., \& Kohout, J. L. (2007). Using workforce analysis to answer questions related to the internship imbalance and career pipeline in professional psychology. Training and Education in Professional Psychology, 1(4), 238-248. https://doi.org/10.1037/1931-3918.1.4.238.

Truscott, S. D., Proctor, S. L., Albritton, K., Matthews, Y., \& Daniel, K. (2014). African American school psychologists' perceptions of the opportunities and challenges of working in the southeastern United States. Psychology in the Schools, 51(4), 366-383. https://doi.org/ 10.1002/pits. 21753.

Walcott, C. M., \& Hyson, D. (2018). Results from the NASP 2015 membership survey, part one: demographics and employment conditions [Research report]. Bethesda: National Association of School Psychologists.

Publisher's Note Springer Nature remains neutral with regard to jurisdictional claims in published maps and institutional affiliations.

Julie Q. Morrison Ph.D., NCSP is an Associate Professor in the School Psychology Program at the University of Cincinnati. Her research interest include evaluating the effectiveness of universal and targeted interventions to address the academic and behavioral needs of schoolage children and youth, program evaluation, and professional accountability.

Susan C. Davies Ed.D., NCSP is a Professor and Coordinator of the School Psychology Program at the University of Dayton. Her research and professional interests include increasing educator awareness of concussions and more severe traumatic brain injuries (TBI), evaluating the efficacy of TBI interventions, and improving service delivery for students who have sustained TBIs.

Amity L. Noltemeyer Ph.D., NCSP is a Professor in School Psychology and the Chair of the Department of Educational Psychology at Miami University. Her research interests include school discipline disparities, resilience, multitiered systems of support, and school-based mental health services. 